\title{
Haematological abnormalities in children with sickle cell disease and non-severe malaria infection in western Kenya
}

\author{
Paul Kosiyo ${ }^{1,2}$, Walter Otieno ${ }^{3}$, Jesse Gitaka ${ }^{4}$, Elly O. Munde ${ }^{5}$ and Collins Ouma ${ }^{1 *}$
}

\begin{abstract}
Background: In Plasmodium falciparum infection, clinical conditions such as anaemia, thrombocytopenia and leukocytosis are common. Mutation in haemoglobin sub-unit beta gene (HBB) may be a genetic factor responsible for these haematological changes during infection. However, the contributions of the carriage of different $H B B$ genotypes on these changes remain largely unknown.

Methodology: In this cross-sectional study, we evaluated haematological abnormalities in $P$. falciparum-infected children ( $n=217$, aged 1-192 months) with different haemoglobin sub-unit beta (HBB) genotypes (HbAA, HbAS and HbSS). Children with acute febrile conditions were recruited at Jaramogi Oginga Odinga Teaching and Referral Hospital at the outpatient clinic. Haematological parameters were determined using Beckman Coulter counter ACTdiff $2^{\text {TM }}$ while HBB genotyping was done using TaqMan ${ }^{\oplus}$ SNP genotyping assay. Chi-square $\left(x^{2}\right)$ was used to determine differences between proportions. Differences in haematological parameters were compared across groups using Kruskal Wallis test and between groups using Mann Whitney $U$ test. Partial correlation test was used to determine correlation between haematological parameters and sickle cell genotypes while controlling for age and sex.
\end{abstract}

Results: Haemoglobin (Hb), [median (IQR); 7.3 (1.3), P = 0.001], haematocrit (HCT), [median (IQR); 26.4 (4.4), $P=0.009$ ], red blood cells (RBC), [median (IQR); $3.2(1.7), P=0.048$ ] were markedly reduced in HbSS, however, red cell distribution with (RDW) [median (IQR); $14.9(3.3), P=0.030$ ] was increased in malaria infected children with $\mathrm{HbSS}$. Severe anaemia was highest in HbSS (23.1\%) followed by HbAA (8.6\%) and HbAS (7.1\%). There were no differences in platelet count $(P=0.399)$ hence no severe thrombocytopeania across the genotypes. Leukocytosis was highest in $\mathrm{HbSS}$ (69.2\%), $42 \%$ in $\mathrm{HbAS}$ and $31 \%$ in $\mathrm{HbAA}$. The RBC, HCT and $\mathrm{Hb}$ had negative correlation with RDW in HbSS in malarial-infected children $(r=-0.725, P=0.008),(r=-0.718, P=0.009)$ and $(r=-0.792, P=0.002)$, respectively.

Conclusion: Our study reveals that anaemia is the most common abnormality in malaria-infected children with carriage of HbSS. The RBC, HCT and Hb concentration decrease with increase in RDW levels in infected children with carriage of HbSS compared to other HBB genotypes. Therefore, carriage of HbSS genotype is correlated with severity of haematological abnormalities.

Keywords: HBB, Genotype, Haematological parameter, P. falciparum

\footnotetext{
* Correspondence: collinouma@yahoo.com

'Department of Biomedical Science and Technology, School of Public Health

and Community Development, Maseno University, Private Bag, Maseno,

Kenya

Full list of author information is available at the end of the article
}

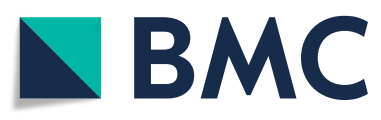

(c) The Author(s). 2021 Open Access This article is licensed under a Creative Commons Attribution 4.0 International License, which permits use, sharing, adaptation, distribution and reproduction in any medium or format, as long as you give appropriate credit to the original author(s) and the source, provide a link to the Creative Commons licence, and indicate if changes were made. The images or other third party material in this article are included in the article's Creative Commons licence, unless indicated otherwise in a credit line to the material. If material is not included in the article's Creative Commons licence and your intended use is not permitted by statutory regulation or exceeds the permitted use, you will need to obtain permission directly from the copyright holder. To view a copy of this licence, visit http://creativecommons.org/licenses/by/4.0/ The Creative Commons Public Domain Dedication waiver (http://creativecommons.org/publicdomain/zero/1.0/) applies to the data made available in this article, unless otherwise stated in a credit line to the data. 


\section{Background}

One of the most important parasitic disease of man is malaria and it is known to claim more lives of children worldwide compared to other infectious diseases [1]. According to WHO estimates, Africa contributes up to 91\% of malaria deaths worldwide [2]. Between the year 2000 and 2017, a significant decline in malaria incidence was achieved [2]. Kisumu County in western Kenya is one of the malaria holoendemic regions in Kenya with malaria prevalence at $27 \%$ [3]. In malaria holoendemic zones, $P$. falciparum is the most deadly and most prevalent species [4]. Severity of malaria varies from person to person and this variation is attributed to both host and parasite factors [5]. P. falciparum malaria severity is characterized by overlapping clinical presentations that include severe malaria anaemia (SMA), respiratory distress, metabolic acidosis, cerebral malaria (CM) and hypoglycaemia [6]. In western Kenya, severe malaria manifest as severe anaemia with $\mathrm{Hb}<6.0 \mathrm{~g} / \mathrm{dL}$ and any density parasitaemia in children below 5 years [7]. Furthermore, several studies in Africa especially in Nigeria [8] and Kenya [9] demonstrated that platelet count is significantly reduced in severe malaria infection and thus recommended the inclusion of thrombocytopenia in case definition of severe malaria. The latter study which was equally conducted in the current study site further determined a correlation between anaemia and thrombocytopenia in $P$. falciparum infected children with normal haemoglobin (HbAA) [9]. However, the above study did not consider different haemoglobin beta sub-unit $(H B B)$ genotypes more so sickle cell gene mutation (6GAG > 6GTG). Moreover, as shown by several studies in western Kenya, it is plausible that SMA in children is as a result of imbalance in the production of both pro-inflammatory and anti-inflammatory mediators, polymorphisms in immune regulatory genes and exacerbations in the presence of co-infections with HIV1 and pathogenic bacteria [10-12]. Whether malaria is severe or non-severe, it is important to note that the overlapping interactions between haemoglobinopathy especially in the haemoglobin beta sub-unit gene $(H B B)$ and malaria, remains a complex biological conundrum that is not well understood [13].

In certain individuals, $H B B$ may contain mutation for the sickle cell gene (6GAG > 6GTG). The $H B B$ mutation (6GAG > 6GTG) is due to nucleotide substitution of thymine for adenine at the sixth codon of $H B B$. This results in incorporation of valine, instead of glutamine culminating into haemoglobin tetramers $(\mathrm{HbS})$ that aggregate into arrays when deoxygenated in the tissues [14]. The global effect of sickle cell disease (SCD) has been projected to be approximately 275,000 deliveries per annum [15] and it is also approximated that it could reach 400, 000 childbirths by 2050 in repute to recent projections.
The geographical distribution of these SCD is very similar to that of malaria and it has been found that SCT confers some resistance to malaria giving a chance to malaria sickle cell disease interface [15]. The P. falciparum infection is habitually fatal in individuals with sickle cell anaemia (HbSS) since the protection from infection seems to operate in $\mathrm{HbS}$ dose-dependent manner thus individuals with $\mathrm{HbSS}$ have an even reduced risk of infection than those with HbAS [16].

Even though sickle cell disease (SCD) is primarily a disease of red blood cells, both leukocytes and thrombocytes are equally affected just like in malaria infection and these are known to drive sickle cell crises via vasoocclusion [17]. This has creating a need to further understand the severities in the context of haematological abnormalities. Additionally, monocytosis has been found to be associated with haemolysis and inflammation in sickle cell anaemia [18]. However, the influence of the carriage of different $H B B$ genotypes (6GAG > 6GTG) on the severities of major haematological abnormalities and correlation of haematological parameters with $H B B$ genotypes (6GAG > 6GTG) once children are infected with $P$. falciparum malaria, remains unknown. As such, we determined the severity of haematological abnormalities and correlation of haematological parameters with different haemoglobin beta subunit $(H B B)$ genotypes in children with $P$. falciparum malaria in Kisumu County, western Kenya.

\section{Materials and methods Study site}

Details on the current study site has been previously described in our publication [19]. In brief, the study was conducted at Jaramogi Oginga Odinga Teaching and Referral Hospital (JOOTRH) in Kisumu County between April 2018 and February 2019. JOOTRH is a major referral hospital in western Kenya and it is located within the headquarters of Kisumu County. Kisumu County is a malaria endemic area with prevalence at $27 \%$ [20].

\section{Study population}

This was a cross-sectional study targeting children aged 1-192 months and resident within Kisumu County (See Supplementary Data File I). The sample size was calculated based on prevalence of sickle cell trait in the study area [21] using Cochran's formula [22]. The details of the study population are described in details in our previous publication [19].

\section{Inclusion criteria}

Children found to be infected with $P$. falciparum upon demonstration of asexual forms of $P$. falciparum through microscopic examination of both thick and thin smear, 
children whose parents were willing and able to provide written informed consent were included in the study.

\section{Exclusion criteria}

Children with previously known forms of haemoglobinopathies e.g. $\alpha$-thalassaemia syndromes, history of sickle cell crises and blood transfusion in the past 3 months, acute bacterial, viral infections and parasitic infections other than P. falciparum, and any form of malignancy and known sickle cell patients on hydroxyurea therapy.

\section{Ethical consideration}

The study was approved by Jaramogi Oginga Odinga Teaching and Referral Hospital Scientific and Ethics Review Committee (JOOTRH-ERC) - Approval NO. ERC.IB/VOL.1/414. All methods were performed in accordance with the relevant guidelines and regulations.

\section{Laboratory procedures}

The details of the laboratory procedures such as haematological measurements, microscopy for demonstration of any asexual form of $P$. falciparum, DNA extraction and quantification are described in details in our previous publication [19]. In summary, haematological measurements were determined using Beckman Coulter counter ACTdiff2 ${ }^{\mathrm{m}}$, P. falciparum infection status was determined by microscopy. PureLink ${ }^{\circ}$ DNA Mini Kit (Invitrogen life technologies, USA) was used for DNA extraction while DNA quality and quantity was assessed using Nano Drop ND-1000 spectrophotometer (Thermofisher Scientific, San Diego, CO, USA) and stored at $-20^{\circ} \mathrm{C}$ prior to use.

\section{$H B B$ rs334 genotyping}

Genotyping of the $H B B$ rs334 SNP was performed using TaqMan $^{\circ}$ SNP Genotyping Assay in accordance with manufacturer's protocols (Life Technologies, Grand Island, NY). Identification of haemoglobin $S$ was from biallellic discrimination (missense change) [Glu6VAL] in the single nucleotide polymorphism rs334 by the following custom primer and probe sequences: ForwardTCAAACAGACACCATGGTGCAT, Reverse-CCCC ACAGGGCAGTAACG, VIC-CTGACTCCTGAG GAGAA-MGB, 6FAM-CTGACTCCTGTGGAGAA$M G B$, respectively and as per our previous work [19]. For quality assurance, a triplicate of control samples obtained from our laboratory archived positive samples for genotype $\mathrm{HbAA}, \mathrm{HbAS}$ and $\mathrm{HbSS}$ were also run. Amplification was performed in Real-time PCR StepOnePlus thermocycler from Applied Biosystems ${ }^{\oplus}$ (Foster City, CA, USA) through an initial denaturation at $95^{\circ} \mathrm{C}$ for $10 \mathrm{~min}$, followed by 40 cycles of denaturation at $95^{\circ} \mathrm{C}$ for $1 \mathrm{~min}$, annealing at $60^{\circ} \mathrm{C}$ for $1 \mathrm{~min}$ and final extension at $72{ }^{\circ} \mathrm{C}$ for $1 \mathrm{~min}$.

\section{Statistical analyses}

Statistical analyses were performed using Statistical Package for the Social Sciences (SPSS) version 22.0 software (IBM, New York, USA). Chi-square $\left(x^{2}\right)$ analysis was used to determine differences between proportions. Mann-Whitney U test and Kruskal Wallis test were used for comparisons of demographic and laboratory characteristics wherever applicable. Further post-hoc pair-wise analysis using Dunn's multiple comparison test was used where there was statistical significance. Partial correlation test was used to determine the correlation between primary red cell measurements and red cell indices in children with carriage of $H B B$ mutation (6GAG > 6GTG) genotypes while controlling for age and sex as confounders. $H B B$ rs334 allele frequencies, consistency and/or deviations from Hardy-Weinberg Equilibrium (HWE) were determined using web-based site http:// www.dr-petrek.eu/documents/HWE.xls. Statistical significance was set at $P \leq 0.05$.

\section{Results}

Demographic characteristics of study participants

Children ( $n=217$, aged 1-192 months) with acute febrile conditions (temperature $>37.5^{\circ} \mathrm{C}$ ) were enrolled in the study. The participants were broadly categorized based on malaria infection status upon microscopic examination and demonstration of any asexual form of $P$. falciparum malaria (trophozoite or schizont) as noninfected $(n=132)$ and infected $(n=85)$. Sex $(P=0.240)$ and age $(P=0.143)$ were comparable between the two groups.

\section{$H B B$ genotype distribution}

Distribution of $H B B$ rs334 genotypes in the study participants was also determined. Among the malaria negative patients, 90 (68.2\%) had HbAA, 31 (23.5\%) had HbAS and $11(8.3 \%)$ had HbSS genotypes while in the infected group, 58 (68.2\%) has HbAA, 14 (16.5\%) had HbAS and 13 (15.3\%) had HbSS genotype. Generally, haemoglobin types were comparable with regard to $P$. falciparum infection, $P=0.743$. The overall genotype distribution for the $H B B$ rs334 deviated significantly from the HWE $\left(X^{2}=32.02, P<0.001\right)$ with a minor allele frequency of 0.21 .

\section{Haematological characteristics of all study participants} Haematological markers for anaemia i.e. haemoglobin, haematocrit and RBC count in those without P. falciparum parasitaemia were higher than those infected with P. falciparum malaria [(median (IQR), $10.5(2.3)$ and 10.1 (3.2), $P=0.022$ ], [(median (IQR), 35.2 (6.8) and 32.8 (9.0), $P=0.009$ ] and [(median (IQR), $4.8(0.7)$ and 4.6 (1.3), $P=0.045]$, respectively. Red cell distribution width (RDW, $P=0.703)$, Mean Corpuscular Volume (MCV, 
$P=0.349)$, Mean Corpuscular Heamoglobin $(\mathrm{MCH}, P=$ 0.744), Mean Corpuscular Haemoglobin Concentration (MCHC, $P=0.479$ ), white blood cells (WBC, $P=0.746$ ), lymphocytes $(P=0.103)$, monocytes $(P=0.084)$, and granulocytes $(P=0.354)$ counts were comparable between the two groups (Table 1). Further analysis revealed that the platelet counts were lower in the infected group [median (IQR), 236 (129.5) vs. non-infected group [median (IQR), 278 (112.8), $P=0.001$, respectively. The mean platelet volume (MPV) were however, not different between the groups $(P=0.119)$. The children with malaria infection further had reduced plateletcrit (PCT), infected [median (IQR), 0.13 (0.1) vs. non-infected [median (IQR), $0.2(0.1), P=0.001$. The platelet distribution width (PDW) were, however, comparable between the groups $(P=0.629)$.

\section{Haematological characteristics of $P$. falciparum infected children}

Haematocrit levels were significantly higher in HbAA [median (IQR), 34.6 (8.3)] and HbAS [median (IQR), 32.8 (6.0)] relative to HbSS [median (IQR), 26.4 (4.4), $P=0.009]$. Furthermore, red blood cell (RBC) count were equally significantly higher in HbAA [median (IQR), 4.6 (1.0)] and HbAS [median (IQR), 4.8 (1.5)] compared to HbSS [median (IQR), 3.2(1.7), $P=0.048$ ]. Nonetheless, Red Cell Distribution Width (RDW) was relatively lower in HbAA [median (IQR), 11.3 (2.2)] and HbAS [median (IQR), 11.5 (2.6)] compared to HbSS [median (IQR), 14.9 (3.3), $P=0.030]$. In cases where significant differences were detected using the KruskalWallis test, we performed a post-hoc pairwise analysis using Dunn's multiple comparison test. The post-hoc

Table 1 General Demographic and Laboratory Characteristics of the Study Participants

\begin{tabular}{|c|c|c|c|c|c|c|c|}
\hline \multicolumn{4}{|c|}{ All the study participants (Infected and non-infected) } & \multicolumn{4}{|c|}{$\begin{array}{l}\text { P. falciparum infected children based on genotype }(n= \\
\text { 85) }\end{array}$} \\
\hline Characteristics & Non-Infected $(n=132)$ & Infected $(n=85)$ & $P$-value & HbAA $(n=58)$ & HBAS $(n=14)$ & HbSS $(n=13)$ & $P$-Value \\
\hline \multicolumn{8}{|l|}{ Sex, n (\%) } \\
\hline Male & $76(57.6)$ & $42(49.4)$ & $0.240^{\mathrm{a}}$ & $30(51.7)$ & $7(50)$ & $8(61.5)$ & $0.690^{\mathrm{a}}$ \\
\hline Female & $56(42.4)$ & $43(50.6)$ & & $28(48.3)$ & $7(50)$ & $5(38.5)$ & \\
\hline Age, (months) & $30(48)$ & $36(55)$ & $0.143^{b}$ & $36(64.5)$ & $36(32.3)$ & $16(27)$ & $0.660^{c}$ \\
\hline \multicolumn{8}{|l|}{ Haemoglobin type } \\
\hline HbAA, n (\%) & $90(68.2)$ & $58(68.2)$ & & & & & \\
\hline $\mathrm{HbAS}, \mathrm{n}(\%)$ & $31(23.5)$ & $14(16.5)$ & $0.743^{\mathrm{a}}$ & & & & \\
\hline HbSS, n (\%) & $11(8.3)$ & $13(15.3)$ & & & & & \\
\hline \multicolumn{4}{|l|}{ Haematological Parameters } & \multicolumn{4}{|c|}{ Haematological Parameters } \\
\hline Haemoglobin, gdL ${ }^{-1}$ & $10.5(2.3)$ & $10.1(3.1)$ & $0.022^{b}$ & $10.2(2.2)$ & $10.4(1.6)$ & $7.3(1.3)$ & $0.001^{c}$ \\
\hline Haematocrit, \% & $35.2(6.8)$ & $32.8(9.0)$ & $0.009^{b}$ & $34.6(8.3)$ & $32.8(6.0)$ & $26.4(4.4)$ & $0.009^{c}$ \\
\hline $\mathrm{RBC},\left(\times 10^{12} \mu \mathrm{L}^{-1}\right)$ & $4.8(0.7)$ & $4.6(1.3)$ & $0.045^{\mathrm{b}}$ & $4.6(1.0)$ & $4.8(1.5)$ & $3.2(1.7)$ & $0.048^{c}$ \\
\hline RDW, \% & $11.7(3.0)$ & $11.6(2.8)$ & $0.703^{b}$ & $11.3(2.2)$ & $11.5(2.6)$ & $14.9(3.3)$ & $0.030^{c}$ \\
\hline$M C V, f L$ & $76.3(11.4)$ & $75.2(10.9)$ & $0.349^{b}$ & $75.2(9.9)$ & $74.1(11.8)$ & $79.5(15.9)$ & $0.415^{c}$ \\
\hline $\mathrm{MCH}, \mathrm{fL} / \mathrm{cell}$ & $22.7(4.3)$ & $22.5(3.7)$ & $0.744^{b}$ & $22.1(3.7)$ & $22.6(4.0)$ & $23.1(3.5)$ & $0.724^{c}$ \\
\hline $\mathrm{MCHC}, \mathrm{gdL}^{-1}$ & $29.6(3.7)$ & $29.8(3.0)$ & $0.479^{b}$ & $29.7(2.5)$ & $30.9(1.7)$ & $27.7(4.1)$ & $0.054^{c}$ \\
\hline WBC $\left(\times 10^{3} \mu \mathrm{L}^{-1}\right)$ & $8.5(6.0)$ & $8.6(5.2)$ & $0.746^{b}$ & $7.8(4.8)$ & $9.58(5.2)$ & $12.68(4.6)$ & $0.078^{c}$ \\
\hline Lymphocytes, $\left(\times 10^{3} \mu \mathrm{L}^{-1}\right)$ & $44.1(25.3)$ & $38(66.9)$ & $0.103^{b}$ & $36.55(27.2)$ & $37(36.2)$ & $50.9(29.1)$ & $0.596^{c}$ \\
\hline Monocytes, $\left(\times 10^{3} \mu \mathrm{L}^{-1}\right)$ & $9.3(4.4)$ & $11.2(7.2)$ & $0.084^{b}$ & $11.2(7.4)$ & $12(7.8)$ & $8.1(6.1)$ & $0.282^{c}$ \\
\hline Granulocytes, $\left(\times 10^{3} \mu \mathrm{L}^{-1}\right)$ & $46.1(26.3)$ & $50.0(25.8)$ & $0.354^{b}$ & $51.4(27.2)$ & $48.9(27.5)$ & $39(28.2)$ & $0.494^{c}$ \\
\hline Platelet Counts, $\left(\times 10^{3} \mu^{-1}\right)$ & $278.0(112.8)$ & $236(129.5)$ & $0.001^{b}$ & $220(1127)$ & $233(129)$ & $236(140)$ & $0.399^{c}$ \\
\hline$M P V, f L$ & $5.5(0.5)$ & $5.40(0.6)$ & $0.119^{b}$ & $5.4(0.6)$ & $5.3(0.9)$ & $5.2(0.8)$ & $0.990^{c}$ \\
\hline $\mathrm{PCT}, \%$ & $0.2(0.1)$ & $0.13(0.1)$ & $0.001^{b}$ & $0.13(0.1)$ & $0.14(0.1)$ & $0.12(0.1)$ & $0.772^{c}$ \\
\hline PDW, \% & $9.4(1.5)$ & $9.5(1.5)$ & $0.629^{b}$ & $9.6(1.4)$ & $9.5(2.0)$ & $9.5(0.40)$ & $0.951^{c}$ \\
\hline
\end{tabular}

Data are presented as the median (interquartile range; IQR) values unless stated otherwise. Study participants were categorized into non-infected and infected (with any density parasitaemia). ${ }^{\text {a }}$ Statistical significance was determined by the Chi-square $\left(x^{2}\right)$ analysis. ${ }^{\text {b }}$ Statistical significance was determined using MannWhitney test. ' Statisitical significance determined by the Kruskal-Wallis test

Abbreviations: HbAA Normal haemoglobin, HbAS Heterozygous sickle cell trait, HbSS Homozygous Haemoglobin S, MCV Mean corpuscular volume, MCH mean corpuscular haemoglobin, $M C H C$ mean corpuscular haemoglobin concentration, WBC White blood cell count, RBC Red blood cells, RDW Red cell distribution width, MPV mean platelet volume, PCT Plateletcrit, PDW Platelet distribution width 
test was run on haemoglobin, haematocrit red blood cell count and red cell distribution width. Our results revealed that haemoglobin was reduced in children with HbSS than those with HbAS $(P=0.001)$. Furthermore, haematocrit was markedly reduced in children with HbSS than those with HbAS $(P=0.002)$. Red blood cell count was reduced in children with HbSS than those with HbAS $(P=0.023)$. However, red cell distribution width was highly raised in children with HbSS than those with HbAS $(P=0.001)$. There were no significant differences in the levels of other hematological indices and carriage of different $H B B$ genotypes in children with $P$. falciparum malaria. These results are summarized in Table 1.

\section{Haematological abnormalities in carriage of different sickle cell genotypes in $P$. falciparum infection}

To determine whether carriage of different sickle cell genotypes have effect on the severity of haematological abnormalities once an individual is infected, we evaluated their severity in children with $P$. falciparum infection and carriage of different sickle cell genotypes. Anaemia was defined according to the World Health Organisation's criteria as a condition where haemoglobin level < $11 \mathrm{~g} / \mathrm{dl}$ in children [23]. These severities were considered as described herein; based on haemoglobin level alone, severity of anaemia was categorised into groups of severe (haemoglobin level $<7 \mathrm{~g} / \mathrm{dl}$ ) mild (haemoglobin level 10$10.9 \mathrm{~g} / \mathrm{dl}$ ), moderate (haemoglobin level $7-9.9 \mathrm{~g} / \mathrm{dl}$ ) and non-anaemic (haemoglobin level $>11 \mathrm{~g} / \mathrm{dl}$ ) [13]. Severe anaemia was seen in $8.6 \%$ of children with $\mathrm{HbAA}, 7.1 \%$ with $\mathrm{HbAS}$ and $23.1 \%$ of those with HbSS. Moderate anaemia was seen in $34.5,21.4$ and $69.2 \%$ of HbAA, HbAS, and $\mathrm{HbSS}$, respectively. Mild anaemia was detected in 22.4\% in $\mathrm{HbAA}, 35.7 \%$ in $\mathrm{HbAS}$ and none in $\mathrm{HbSS}$. Otherwise, non-anaemic children were also seen in 34.5, 37.5 and $7.7 \%$ in those with HbAA, HbAS and HbSS genotypes, respectively.

Thrombocytopenia was defined as a haematological condition in which platelet count is below $150 \times 10^{3} \mu \mathrm{L}^{-1}$ of blood [24]. For evaluation purposes, severity of thrombocytopenia was categorized as severe (platelet count $<50 \times 10^{3} \mu \mathrm{L}^{-1}$ ), moderate (platelet count between 50 and $100 \times 10^{3} \mu \mathrm{L}^{-1}$ ) and mild (platelet count between 100 and $150 \times 10^{3} \mu \mathrm{L}^{-1}$ ). Otherwise, any platelet count above $150 \times 10^{3} \mu \mathrm{L}^{-1}$ was considered non-thrombocytopenic. None of the participants demonstrated severe thrombocytopenia in any of the $H B B$ genotypes. Moderate thrombocytopenia was seen in 5.2 and $7.1 \%$ of HbAA and HbAS, respectively. However, none had thrombocytopenia in children with HbSS genotype. Mild thrombocytopenia was demonstrated in 15.5, 7.1 and 15.4\% in individuals with HbAA, HbAS and HbSS, respectively. However, nonthrombocytopenia was demonstrated in $79.3 \%$ of children with $\mathrm{HbAA}, 85.7 \%$ of children with $\mathrm{HbAS}$ and $11 \%$ of children with $\mathrm{HbSS}$.

Leucocytopenia was defined as a condition in which total leucocyte count is below $4 \times 10^{3} \mu \mathrm{L}^{-1}$ of blood. There was no leucocytopenia in any of the study participants. Leukocytosis was defined as a benign abnormality in which total leucocyte count is above $11 \times 10^{3} \mu \mathrm{L}^{-1}$ ) of blood [24]. Leukocytosis was demonstrated in 31\% of children with HbAA, $42.9 \%$ in children with HbAS and in $69.2 \%$ of children with HbSS. Normal leucocyte count (WBC count between $\left(4-11 \times 10^{3} \mu \mathrm{L}^{-1}\right)$ was seen in $70 \%$ of those with HbAA genotype, $57.1 \%$ in those with $\mathrm{HbAS}$ and in $30.8 \%$ in those with HbSS genotype.

Monocytosis was defined as a condition in which total monocyte count is below $12 \%$ of the total white blood cell count in peripheral blood [24, 25]. Monocytosis was seen in $59 \%$ in children with $\mathrm{HbAA}, 79 \%$ in children with $\mathrm{HbAS}$ and in $31 \%$ in children with HbSS genotype. The distribution of severity of anaemia, thrombocytopenia, leukocytosis, leucocytopaenia and monocytosis are summarized in Table 2.

\section{Correlations between primary red cell measurements and red cell indices in children with carriage of different $H B B$ genotypes (6GAG > 6GTG mutation)}

Using partial correlation test while controlling for age and sex as factors that have previously been shown to affect haematological indices [26], the study revealed that in the HbSS genotype group, the RBC count had a negative correlation with RDW in children malariainfected and non-infected $(r=-0.750, P=0.008$ and $r=$ $-0.634, P=0.049$, respectively). Furthermore, there was a negative correlation between RBC count and both $\mathrm{MCV}$ and $\mathrm{MCH}$ in malaria-infected children $(r=-$ $0.833, P=0.001)$ and $(r=-0.750, P=0.005)$, respectively. Haematocrit was negatively correlated with RDW in both malaria-infected and non-infected children $(r=-$ $0.918, P=0.001)$ and $(r=-0.718, P=0.009)$, respectively. Additional analysis in the carriage HbAS genotype, showed a negative correlation between haemoglobin with RDW in malaria-uninfected children $(r=-0.694$, $P<0.0001)$. The RBC count showed a negative correlation with $\mathrm{MCV}(r=-0.752, P=0.003)$ and with $\mathrm{MCH}$ $(r=-0.797, P=0.001)$ in malaria-infected children.

In HbAA genotype, RBC count showed a negative correlation with $\mathrm{MCV}(r=-0.324, P=0.002), \mathrm{MCH}(r=-$ $0.273, P=0.010), \operatorname{MCHC}(r=-0.401, P=0.000)$ and RDW $(r=-0.235, P=0.027)$ in children without malaria infection. Haematocrit showed a positive correlation with MCV $(r=0.524, P<0.0001)$, and a negative correlation with MCHC $(r=-0.333, P=0.001)$ and RDW $(r=$ -0.361, $P<0.0001)$ in children without malaria infection. Haemoglobin showed a positive correlation with $\operatorname{MCV}(r=0.525, P<0.0001), \mathrm{MCH}(r=0.408, P<0.0001)$ 
Table 2 Distribution and severity of selected haematological abnormalities with regard to haemoglobin type in P. falciparum infected children

\begin{tabular}{|c|c|c|c|c|c|}
\hline \multirow{2}{*}{$\begin{array}{l}\text { Haematological } \\
\text { parameter }\end{array}$} & \multirow{2}{*}{$\begin{array}{l}\text { Severity of the } \\
\text { Haematological } \\
\text { Abnormalities }\end{array}$} & \multicolumn{3}{|c|}{$H B B$ genotypes } & \multirow{2}{*}{$\begin{array}{l}\text { Total } \\
\text { n (\%) }\end{array}$} \\
\hline & & $\begin{array}{l}\mathrm{HbAA} \\
\mathrm{n}(\%)\end{array}$ & $\begin{array}{l}\mathrm{HbAS} \\
\mathrm{n}(\%)\end{array}$ & $\begin{array}{l}\mathrm{HbSS} \\
\mathrm{n}(\%)\end{array}$ & \\
\hline \multirow[t]{5}{*}{ Haemoglobin } & Severe anaemia & $5(8.6)$ & $1(7.1)$ & $3(23.1)$ & $9(10.5)$ \\
\hline & Moderate anaemia & $20(34.5)$ & $3(21.4)$ & $9(69.2)$ & $32(42.4)$ \\
\hline & Mild anaemia & $13(22.4)$ & $5(35.7)$ & $0(0)$ & $18(21.2)$ \\
\hline & Non-anaemic & $20(34.5)$ & $5(35.7)$ & $1(7.7)$ & $25(29.4)$ \\
\hline & Total & 58 & 14 & 13 & 85 \\
\hline \multirow[t]{5}{*}{ Platelets } & Severe thrombocytopenia & $0(0)$ & $0(0)$ & $0(0)$ & $0(0)$ \\
\hline & Moderate thrombocytopenia & $3(5.2)$ & $1(7.1)$ & $0(0)$ & $4(4.7)$ \\
\hline & Mild thrombocytopenia & $9(15.5)$ & $1(7.1)$ & $2(15.4)$ & $12(14.1)$ \\
\hline & Non-thrombocytopenia & $46(79.3)$ & $12(85.7)$ & $11(84.6)$ & $69(81.2)$ \\
\hline & Total & 58 & 14 & 13 & 85 \\
\hline \multirow[t]{4}{*}{ Leukocytes } & Leukocytopaenia & $0(0)$ & $0(0)$ & $0(0)$ & $0(0)$ \\
\hline & Leukocytosis & $18(31)$ & $6(42.9)$ & $9(69.2)$ & $33(38.8)$ \\
\hline & Normal & $40(70)$ & $8(57.1)$ & $4(30.8)$ & $52(61.2)$ \\
\hline & Total & 58 & 14 & 13 & 85 \\
\hline \multirow[t]{3}{*}{ Monocytes } & Monocytosis & $34(59)$ & $11(79)$ & $4(31)$ & $49(58)$ \\
\hline & Normal & $24(41)$ & $3(21)$ & $9(69)$ & $36(42)$ \\
\hline & & 58 & 14 & 13 & 85 \\
\hline
\end{tabular}

Data are presented as proportions ( $\mathrm{n}$ ) and percentages (\%) of different $H B B$ genotypes and different severities of haematological abnormalitis in children infected with P.falciparum malaria

and MCHC $(r=0.269, P=0.011)$, however, it showed a negative correlation with RDW $(r=-0.664, P<0.0001)$ in children without malaria infection. The $\mathrm{RBC}$ showed a negative correlation with $\mathrm{MCV}(r=-0.393, P=0.003)$, $\mathrm{MCH}(r=-0.408, P=0.002)$, MCHC $(r=-0.270, P=$ $0.043)$ and RDW $(r=-0.399, P=0.002)$ in malariainfected children. There was a negative correlation between haematocrit and PDW $(r=-0.446, P=0.001)$ in children infected with malaria. Haemoglobin showed positive correlation with $\mathrm{MCH}(r=0.317, P=0.016)$ and MCHC $(r=0.269, P=0.011)$ in children infected with $P$. falciparum malaria. Further analysis revealed a negative correlation between haemoglobin and RDW ( $r=-0.479$, $P=0.001)$ in children infected with $P$. falciparum malaria and $(r=-0.479, P=0.001)$ in children without $P$. falciparum malaria. It is therefore probable that the RBC count, haematocrit and haemoglobin concentration decrease with increase in RDW levels in P. falciparum-infected children with carriage of HbSS genotype relative to other $H B B$ genotypes. Correlation between primary red cell measurements and red cell indices are summarized in Table 3 .

\section{Discussion}

Children from Sub-Saharan Africa continue to bear the largest burden of P. falciparum malaria [2]. Haematological changes or abnormalities are some of the most common complications in malaria and they play a major role in malaria pathogenesis [27, 28]. Previous studies have reported that haematological parameters are affected by $P$. falciparum infection and mutations in the $H B B$ gene $[19,27,29]$. The presence of the sickle cell mutation has been shown to influence malaria outcome in populations where the infection is endemic [30] such as western Kenya. In the current study, we initially determined the allele frequency of the $H B B$ rs334 in this population. Our results showed that the minor allele frequency $(\mathrm{S})$ was 0.21 , which is consistent with previous studies in other malaria endemic parts of Sub-Saharan Africa [31, 32]. The HWE inconsistency of the $H B B$ rs334 allele distributions observed in the current study emphases that malaria infection is an important factor driving genetic drift towards sickle cell. In the current study, therefore, we determined severity of haematological abnormalities and correlation of haematological parameters with $H B B$ genotypes in children with $P$. falciparum malaria in Kisumu County, western Kenya, a $P$. falciparum holoendemic region.

Our current study reveals the presence of severe anaemia in malaria-infected children with HbSS genotype. This observation could be due to chronic haemolysis observed in sickle cell anaemia [33] and accelerated sickling of infected RBCs culminating into ultimate clearance [34]. In addition, this could also be 
Table 3 Correlation of haematological parameters with Sickle cell genotype in children with and without $P$. falciparum infection

\begin{tabular}{|c|c|c|c|c|c|c|c|c|c|c|}
\hline \multirow{2}{*}{ Control Variable } & & & \multicolumn{4}{|c|}{ Malaria negative $(N=132)$} & \multicolumn{4}{|c|}{ Malaria positive $(N=85)$} \\
\hline & & & MCV (fL) & $\mathrm{MCH}(\mathrm{Pg})$ & $\mathrm{MCHC}\left(\mathrm{gdL}^{-}\right)$ & RDW (\%) & MCV (fL) & $\mathrm{MCH}(\mathrm{Pg})$ & $\mathrm{MCHC}\left(\mathrm{gdL}^{-}\right)$ & RDW (\%) \\
\hline \multicolumn{7}{|c|}{ Sickle cell anaemia $(\mathrm{HbSS})(n=11)$} & \multicolumn{4}{|c|}{ Sickle cell anaemia (HbSS) $(n=13)$} \\
\hline \multirow[t]{6}{*}{ Age and sex } & RBC count & r & -0.362 & -0.068 & 0.060 & -0.634 & -0.883 & -0.750 & -0.118 & -0.725 \\
\hline & & $P$ value & 0.304 & 0.852 & 0.870 & 0.049 & 0.001 & 0.005 & 0.715 & 0.008 \\
\hline & Haematocrit & r & 0.231 & 0.172 & -0.086 & -0.918 & -0.555 & -0.418 & 0.273 & -0.718 \\
\hline & & $P$ value & 0.521 & 0.635 & 0.813 & $<0.0001$ & 0.061 & 0.176 & 0.391 & 0.009 \\
\hline & Haemoglobin & r & -0.218 & 0.032 & 0.563 & -0.616 & -0.526 & -0.220 & 0.521 & -0.792 \\
\hline & & $P$ value & 0.545 & 0.929 & 0.090 & 0.058 & 0.079 & 0.493 & 0.082 & 0.002 \\
\hline \multicolumn{7}{|c|}{ Sickle cell trait $(\mathrm{HbAS})(n=31)$} & \multicolumn{4}{|c|}{ Sickle cell trait (HbAS) $(n=14)$} \\
\hline \multirow[t]{6}{*}{ Age and sex } & RBC count & r & -0.299 & -0.494 & -0.434 & -0.292 & -0.752 & -0.797 & -0.305 & -0.392 \\
\hline & & $P$ value & 0.116 & 0.006 & 0.019 & 0.125 & 0.003 & 0.001 & 0.311 & 0.185 \\
\hline & Haematocrit & r & 0.515 & 0.221 & -0.458 & -0.507 & -0.269 & -0.369 & -0.394 & -0.506 \\
\hline & & $P$ value & 0.004 & 0.249 & 0.013 & 0.005 & 0.375 & 0.214 & 0.183 & 0.078 \\
\hline & Haemoglobin & r & 0.547 & 0.533 & 0.069 & -0.694 & -0.247 & -0.235 & -0.080 & -0.475 \\
\hline & & $P$ value & 0.002 & 0.003 & 0.720 & $<0.0001$ & 0.417 & 0.441 & 0.796 & 0.101 \\
\hline \multicolumn{7}{|c|}{ Normal haemoglobin $(\mathrm{HbAA})(n=90)$} & \multicolumn{4}{|c|}{ Normal haemoglobin $(\mathrm{HbAA})(n=58)$} \\
\hline \multirow[t]{6}{*}{ Age and sex } & RBC count & r & -0.324 & -0.273 & -0.401 & -0.235 & -0.393 & -0.408 & -0.270 & -0.399 \\
\hline & & $P$ value & 0.002 & 0.010 & $<0.0001$ & 0.027 & 0.003 & 0.002 & 0.043 & 0.002 \\
\hline & Haematocrit & $r$ & 0.524 & 0.143 & -0.333 & -0.361 & 0.139 & .076 & -0.072 & -0.446 \\
\hline & & $P$ value & $<0.0001$ & 0.181 & 0.001 & $<0.0001$ & 0.302 & 0.573 & 0.593 & 0.001 \\
\hline & Haemoglobin & $r$ & 0.525 & 0.408 & 0.269 & -0.664 & 0.257 & 0.317 & 0.285 & -0.479 \\
\hline & & $P$ value & $<0.0001$ & $<0.0001$ & 0.011 & $<0.0001$ & 0.053 & 0.016 & 0.032 & 0.001 \\
\hline
\end{tabular}

Data are the partial correlations $(r)$. Malaria negative patients $(n=132)$ and malaria positive patients $(n=85)$ with acute febrile illness were categorized on the basis of haemoglobin type. All statistical significance was determined by the partial correlation test $(r)$ controlling for age and sex. Values in bold are statistically significant at $P \leq 0.05$

Abbreviations: MCV Mean corpuscular volume, MCH mean corpuscular haemoglobin, MCHC mean corpuscular haemoglobin concentration, RBC-Red blood cells, $R D W$ Red cell distribution width, $r$ the measure of strength of Pearson's correlation

contributed by background haemolytic anaemia and autosplenectomy that occurs in children with HbSS [35, 36 and invasion of red cells of HbSS genotype by merozoites, which represents an external stressor that would make the cells to haemolyse before the parasites have a chance to reproduce [37]. Our finding that the hematocrit was lower in HbSS genotype was not surprising. The lower levels of haemoglobin contributes to low haematocrit percentage as a result of continuous haemolytic process in the carriage of $\mathrm{HbSS}$, which then would lower the proportion of red blood cells in relation to the whole blood volume [26]. Our analysis also revealed that children with severe anaemia in HbSS genotype and infected with $P$. falciparum infection had increased red cell distribution width. The increased RDW in HbSS reported in the current study is explainable by pre-existing anisocytosis and poikilocytosis, which have been previously reported to be common biological conundrum in sickle cell disease $[25,26]$. Increased RDW is further be attributed to existence of both mature normocytic cells and immature macrocytic red cell which have been prematurely released from the bone marrow in a compensatory response to chronic haemolysis in children with sickle cell [33]. The absence of anaemia in the smaller proportion of $P$. falciparum-infected children with $\mathrm{HbSS}$ genotype could be a modulated hereditary persistence of foetal haemoglobin (HPFH) [38]. It would be scientifically sound to explore this hypothesis in further studies.

The presence of mild and moderate anaemia was observed in children infected with $P$. falciparum and had the carriage of HbAA genotype. Even though the mechanism was not explored in the current study, this phenomena is attributable to reduced haemolytic mechanisms and slowed removal of infected red blood cells by erythro-phagocytosis in non-severe malaria [39]. Our findings demonstrate that the carriage of HbAA genotype is important in reducing anaemia severity. On the other hand, the observed few severe anaemia in the HbAA group could be due to increased haemolytic mechanisms and accelerated removal of infected red blood cells by erythro-phagocytosis and ineffective 
erythropoiesis [39]. The minimal severity of anaemia observed in the carriage of HbAS could be attributed to other anaemia-promoting conditions like poor nutritional status and infections such as HIV-1 and bacteremia [40], which the current study did not have the opportunity and ethical approvals to investigate. Other investigations have also implicated reduced anaemia (mild to moderate) in children with HbAS genotype relative to HbAA genotype and suggested that high levels of RBC complement regulatory proteins (CR1 and CD55) play a role in the pathogenesis of severe anaemia in malaria infection $[41,42]$. Further, it is important to note that more children with the carriage of the HbAS genotype had mild to moderate anaemia and that children with carriage of the HbSS genotype and infected with P. falciparum infection had the lowest haemoglobin level as compared to HbAS and HbAA patients. This finding showed consistency with the findings of a similar study in hospitalized Cameroonian children with sickle cell anaemia and infected with malaria [43].

Even though lower platelet count was seen in the infected children relative to non-infected children in HbAA genotypes, it did not differ across other genotypes (HbSS vs. HbAS). This means that thrombocytopenia was not demonstrated in carriage of any haemoglobin type during $P$. falciparum infection. Our study did not find thrombocytopenia as a haematogical abnormality in children with $P$. falciparum malaria irrespective of the $H B B$ genotypes. However, this finding differed from earlier studies which demonstrated thrombocytopenia in HbAA genotype individuals infected with $P$. falciparum $[8,9,27]$. This reported inconsistency in our study is attributable to the fact that study participants in the current study only suffered from non-severe malaria while in the previous study, the participants suffered from severe malaria. Previous studies have reported thrombocytopenia in P. falciparum infection and attributed this to peripheral destruction of platelets and their consumption by disseminated intravascular coagulation process, as well as splenic pooling [44]. On the other hand, thrombocytosis has been reported in HbSS individuals who are not infected with malaria [29]. Our finding needs further explorations since absence of thrombocytopenia and thrombocytosis which are known to be benign abnormalities of thrombocytes would not require any clinical intervention.

Our study further showed that children with HbSS genotype and infected with malaria had reduced monocytosis compared to those with HbAA and HbAS genotypes. A previous study showed a positive correlation between monocyte to lymphocyte ratio in the presence of malaria and the level of parasitaemia [45]. Furthermore, a previous study in the current study location demonstrated that monocytosis is the most important leucocytic change associated with $P$. falciparum malaria infection [27]. Monocytosis has been previously reported to drive sickle cell vaso-occlusion $[17,36]$ and it has also been reported to be associated with haemolysis and inflammation in sickle cell anaemia [18]. Monocytes are thought to be activated in sickle cell anaemia by the expression of TNF-alpha and IL-1 beta as well as the adhesion of molecule ligand (CD11b) [46-48]. Perhaps this could be an additional reason behind the utilization of hydroxyurea to alter the circulating monocyte subsets and to dampen its inflammatory potential in sickle patients apart from raising the level of fetal haemoglobin (HbF) [49]. In contrast, a previous study reported monocytopenia being associated with severe malaria and adverse outcome [44]. Initially, our finding revealed no significant difference in leucocyte count between malaria-infected versus non-infected children. Contrary to our finding, other studies have demonstrated leukocytosis [44,50] while others have demonstrated leucocytopenia [51-53] in malaria-infected children with HbAA. Finding of the current study is comparable with other previous studies $[27,54,55]$, which reported no significant differences between malaria-infected and non-infected children. Furthermore, leukocytosis was highest in the carriage of HbSS genotype in children infected with $P$. falciparum malaria. This finding was not surprising since it has been previously established that leukocytosis is a common biological response in severe malaria anaemia to counter the infection [56]. It is also important to point out that leucocyte adhesion and activation are major causes of sickle cell vaso-occlusion in sickle cell anaemia [57].

Mutations in haemoglobin beta sub-unit gene ( $H B B)$ have been found to primarily affect the red blood cells structurally resulting into sickle cell and physiologically affecting normal red cell functions [58]. However, it is not known how primary red cell measurement correlate with red cell indices in individuals infected with $P$. falciparum and presenting with different $H B B$ (6GAG > 6GTG) genotypes. Erythrocyte counts revealed a strong negative correlation with RDW in children infected with malaria and had carriage of the HbSS genotype. Furthermore, this correlation trend was also seen in the malaria-infected children with the carriage of HbAS and HbAA. This implies that increasing the RDW reduces the erythrocyte counts once an individual is infected and this situation is aggravated by carriage of the HbSS genotype. These findings therefore demonstrate the effects of malaria infection on haematological parameters [59] and the effect of HbSS genotype on exacerbation of haematological abnormalities observed during infection.

Limitation in the current study included fewer number of subjects in $\mathrm{HbAS}$ and HbSS, lack of information on the nutritional status of the participants, possible 
presence of other co-infections e.g. HIV, bacteremia and intestinal infections such as hookworm and tapeworm which have been previously reported to worsen anaemia [40, 60, 61]. In addition, our study did not measure levels of fetal haemoglobin ( $\mathrm{HbF})$ as the most important biomarker for disease prognosis in SCD. The current study did not incorporate differential leucocyte count to give more insight to benign changes in cells of granulocytic series. Additionally, we lacked knowledge on the most recent malaria infectivity rate following several malaria control interventions in the study area and nonuniformity in the exposure of subjects to mosquitoes' bites.

\section{Recommendation}

We recommend that a similar longitudinal study with a larger sample size should be conducted in the same study area taking into account the level of $\mathrm{HbF}$ among other haematological parameters, as this may be more informative. We equally recommend inclusion of laboratory investigations of bacteremia and parasitic infections.

\section{Conclusion}

Our study reveals that anaemia is the most common haematological abnormality in malaria-infected children with carriage of HbSS genotype. The RBC count, haematocrit and haemoglobin concentration decrease with increase in RDW levels in $P$. falciparum-infected children with carriage of HbSS genotype compared to other $H B B$ genotypes. Therefore, carriage of HbSS genotype contributes to the severity of haematological abnormalities once a child is infected P. falciparum.

\section{Abbreviations \\ CR1: Complement regulatory protein 1; CD55: Cluster of differentiation 55; CD11b: Cluster of differentiation 11b; HbAA: Genotype of the normal haemoglobin; HbAS: Genotype in sickle cell trait; HbSS: Genotype in sickle cell anaemia; HWE: Hardy Weinberg Equilibrium; MCH: Mean corpuscular haemoglobin; MCHC: Mean corpuscular haemoglobin concentration; MCV: Mean corpuscular volume; PBF: Peripheral blood film examination; PCR: Polymerase Chain Reaction; RBC: Red cell count; RDW: Red cell distribution width}

\section{Supplementary Information}

The online version contains supplementary material available at https://doi. org/10.1186/s12879-021-06025-7.

\section{Additional file 1}

\section{Acknowledgements}

We are grateful to the Chief Administrator and the Ethical Review Committee of Jaramogi Oginga Odinga Teaching and Referral Hospital. The authors are grateful to clinical staff of JOOTRH who helped facilitate the activities at the hospital. We also express our sincere gratitude to children, their guardians as well as the adults who participated in this study. In a special way, we are grateful to the laboratory staff for their good cooperation and hard work during the collection and analyses of clinical specimens.

\section{Authors' contributions}

PK, EOM, WO, JG and CO designed, carried out the study in the population and participated in the drafting of the manuscript. PK and CO performed the statistical analyses and participated in the drafting of the manuscript. All authors read and approved the final manuscript.

\section{Funding}

This work did not receive any funding from any institution.

\section{Availability of data and materials}

The datasets generated and/or analyzed during the current study are not publicly available due compliance with ethical reviewer guidelines but are obtainable from the corresponding author on reasonable request.

\section{Declarations}

Ethics approval and consent to participate

The study was approved by the Jaramogi Oginga Odinga Teaching and Referral Hospital (JOOTRH) Ethical Review committee. All participants provided written informed consent to participate in the study. The parents/ guardians provided informed consent for their children to participate in the study.

\section{Consent for publication}

Not applicable.

\section{Competing interests}

The authors have declared no competing interest.

\section{Author details}

'Department of Biomedical Science and Technology, School of Public Health and Community Development, Maseno University, Private Bag, Maseno, Kenya. ${ }^{2}$ Department of Medical Laboratory Sciences, School of Medicine, Maseno University, Private Bag, Maseno, Kenya. ${ }^{3}$ Department of Paediatrics and Child Health, School of Medicine, Maseno University, Private Bag, Maseno, Kenya. ${ }^{4}$ Directorate of Research and Innovation, Mount Kenya University, General Kago Road, P.O. Box 342-01000, Thika, Kenya.

${ }^{5}$ Department of Clinical Medicine, School of Health Sciences, Kirinyaga University, P.O. Box 143-10300, Kerugoya, Kenya.

Received: 8 January 2021 Accepted: 30 March 2021

Published online: 07 April 2021

\section{References}

1. Newton PN, Fernández FM, Plançon A, Mildenhall DC, Green MD, Ziyong L, et al. A collaborative epidemiological investigation into the criminal fake artesunate trade in South East Asia. PLoS Med. 2008;5(2):e32. https://doi. org/10.1371/journal.pmed.0050032.

2. WHO. World malaria report 2020: 20 years of global progress and challenges. Geneva: World Health Organization; 2020. Licence: CC BY-NC-SA 3.0 IGO; 2020

3. KNBS: The 2015 Kenya Malaria Indicator Survey. National Malaria Control Programme Ministry of Health Kenyatta National Hospital, Nairobi 00202, Kenya; telephone: +254 20271 6934/5; fax: +254 20271 6935; e-mail: headdomc@domckenyaorke; Internet: wwwnmcporke 2016.

4. Akanda TM. Epidemiology of malaria in Africa. Afr J Clin Exp Microbiol. 2005; 6(2):107-11.

5. Acharya P, Garg M, Kumar P, Munjal A, Raja KD. Host-parasite interactions in human malaria: clinical implications of basic research. Front Microbiol. 2017; 8:889. https://doi.org/10.3389/fmicb.2017.00889.

6. Rowe JA, Opi DH, Williams TN. Blood groups and malaria: fresh insights into pathogenesis and identification of targets for intervention. Curr Opin Hematol. 2009;16(6):480-7. https://doi.org/10.1097/MOH.0b013e3283313de0.

7. McElroy PD, ter Kuile FO, Lal AA, Bloland PB, Hawley WA, Oloo AJ, et al. Effect of Plasmodium falciparum parasitemia density on hemoglobin concentrations among full-term, normal birth weight children in western Kenya, IV. The Asembo Bay cohort project. Am J Trop Med Hyg. 2000;62(4): 504-12. https://doi.org/10.4269/aitmh.2000.62.504.

8. Erhabor O, Mohammad HJ, Onuigue FU, Abdulrahaman Y, Ezimah AC, et al. Anaemia and Thrombocytopenia among Malaria Parasitized Children in Sokoto, North Western Nigeria. J Hematolo Trans. 2014;2(2):1020. 
9. Mboya PK, Sumba PO, Oluoch JN, Abdallah FK, Mala AO. Correlation between thrombocytopenia and anaemia in plasmodium falciparum malaria among patients in Kisumu County-Western Kenya. Afr J Health Sci. 2016;29(2):76-88.

10. Munde EO, Raballah E, Okeyo WA, Ong'echa JM, Perkins DJ, Ouma C. Haplotype of non-synonymous mutations within IL-23R is associated with susceptibility to severe malaria anemia in a P. falciparum holoendemic transmission area of Kenya. BMC Infect Dis. 2017;17(1):291.

11. Ouma C, Davenport GC, Awandare GA, Keller CC, Were T, Otieno MF, et al. Polymorphic variability in the interleukin (IL)-1beta promoter conditions susceptibility to severe malarial anemia and functional changes in IL-1beta production. J Infect Dis. 2008;198(8):1219-26. https://doi.org/10.1086/592055.

12. Perkins DJ, Were T, Davenport GC, Kempaiah P, Hittner JB, Ong'echa JM. Severe malarial anemia: innate immunity and pathogenesis. Int J Biol Sci. 2011;7(9):1427-42. https://doi.org/10.7150/ijbs.7.1427.

13. Albiti AH, Nsiah K. Comparative haematological parameters of HbAA and HbAS genotype children infected with plasmodium falciparum malaria in Yemen. Hematol. 2014;19(3):169-74. https://doi.org/10.1179/1607845413Y. 0000000113.

14. Serjeant GR, Vichinsky E. Variability of homozygous sickle cell disease: the role of alpha and beta globin chain variation and other factors. Blood Cells Mol Dis. 2018;70:66-77. https://doi.org/10.1016/j.bcmd.2017.06.004

15. Piel FB, Patil AP, Howes RE, Nyangiri OA, Gething PW, Williams TN, et al. Global distribution of the sickle cell gene and geographical confirmation of the malaria hypothesis. Nat Commun. 2010;1(1):104. https://doi.org/10.1038/ ncomms 1104

16. Aluoch JR. The presence of sickle cells in the peripheral blood film. Specificity and sensitivity of diagnosis of homozygous sickle cell disease in Kenya. Trop Geogr Med. 1995;47(2):89-91.

17. Wonkam A, Mnika K, Ngo Bitoungui VJ, Chetcha Chemegni B, Chimusa ER, Dandara C, et al. Clinical and genetic factors are associated with pain and hospitalisation rates in sickle cell anaemia in Cameroon. Br J Haematol. 2018;180(1):134-46. https://doi.org/10.1111/bjh.15011.

18. Wongtong $\mathrm{N}$, Jones S, Deng Y, Cai J, Ataga Kl. Monocytosis is associated with hemolysis in sickle cell disease. Hematol. 2015;20(10):593-7. https://doi. org/10.1179/1607845415Y.0000000011.

19. Kosiyo P, Otieno W, Gitaka J, Munde EO, Ouma C. Association between haematological parameters and sickle cell genotypes in children with plasmodium falciparum malaria resident in Kisumu County in Western Kenya. BMC Infect Dis. 2020;20(1):887. https://doi.org/10.1186/s12879-02005625-z.

20. KNBS: The 2015 Kenya Malaria Indicator Survey. National Malaria Control Programme of the Ministry of Health, 19982, Kenyatta National Hospital, Nairobi 00202, Kenya; telephone: +254 20271 6934/5; fax: +254 20271 6935; e-mail: headdomc@domckenyaorke; Internet: wwwnmcporke 2016.

21. Otieno W, Estambale B, Michael MO, Gondi SM, Aluoch JR, Stoute JA. Sickle cell trait $(\mathrm{HbAS})$ is associated with increased expression of erythrocyte complement regulatory proteins CR1 and CD55 levels in children. Int J Trop Dis Health. 2013;3(2):133-47.

22. Cochran WG. Sampling techniques. 2nd ed. New York: Wiley; 1963.

23. WHO: Haemoglobin concentration for diagnosis of severe anaemia and assessment of severity. 2014. http;//wwwwhoint/vmnis/indicators/ haemoglobinpdf.

24. Gitaka J, Ogwang C, Ngari M, Akoo P, Olotu A, Kerubo C, et al. Clinical laboratory reference values amongst children aged 4 weeks to 17 months in Kilifi, Kenya: a cross sectional observational study. PLoS One. 2017;12(5): e0177382. https://doi.org/10.1371/journal.pone.0177382.

25. Palmer L, Briggs C, McFadden S, Zini G, Burthem J, Rozenberg G, et al. ICSH recommendations for the standardization of nomenclature and grading of peripheral blood cell morphological features. Int J Lab Hematol. 2015;37(3): 287-303. https://doi.org/10.1111/ijlh.12327.

26. Hoffbrand AV, Moss PAH, Pettit JE. Essential Haematology, vol. 5. Birmingham: Blackwell Publishing; 2006. p. 249.

27. Maina RN, Walsh D, Gaddy C, Hongo G, Waitumbi J, Otieno L, et al. Impact of Plasmodium falciparum infection on haematological parameters in children living in Western Kenya. Malar J. 2010;9(Suppl 3):S4.

28. Warimwe GM, Murungi LM, Kamuyu G, Nyangweso GM, Wambua J, Naranbhai $V$, et al. The ratio of monocytes to lymphocytes in peripheral blood correlates with increased susceptibility to clinical malaria in Kenyan children. PLoS One. 2013;8(2):e57320. https://doi.org/10.1371/journal.pone. 0057320 .
29. Purohit P, Mohanty PK, Patel S, Das P, Panigrahi J, Das K. Comparative study of clinical presentation and hematological indices in hospitalized sickle cell patients with severe plasmodium falciparum malaria. J Infect Public Health. 2018;11(3):321-5. https://doi.org/10.1016/j.jiph.2017.08.013.

30. Luzzatto L. Sickle cell anaemia and malaria. Mediter J Hematol Infect Dis. 2012;4(1):e2012065. https://doi.org/10.4084/mjhid.2012.065.

31. Bougouma EC, Tiono AB, Ouedraogo A, Soulama I, Diarra A, Yaro JB, et al. Haemoglobin variants and plasmodium falciparum malaria in children under five years of age living in a high and seasonal malaria transmission area of Burkina Faso. Malar J. 2012;11(1):154. https://doi.org/10.1186/1475-2875-11-154.

32. Modiano D, Bancone G, Ciminelli BM, Pompei F, Blot I, Simporé J, et al. Haemoglobin S and haemoglobin C: 'quick but costly' versus 'slow but gratis' genetic adaptations to plasmodium falciparum malaria. Hum Mol Genet. 2008;17(6):789-99. https://doi.org/10.1093/hmg/ddm350.

33. Omoti CE. Haematological values in sickle cell anaemia in steady state and during vaso-occlusive crisis in Benin City, Nigeria. Ann Afr Med. 2005;4:62-7.

34. Luzzatto L, Nwachuku-Jarrett ES, Reddy S. Increased sickling of parasitized erythrocytes as mechanism of resistance against malaria in the sickle trait. Lancet. 1970;1:319-21.

35. Akinbami A, Dosunmu A, Adediran A, Oshinaike O, Adebola P, Arogundade O. Haematological values in homozygous sickle cell disease in steady state and haemoglobin phenotypes AA controls in Lagos, Nigeria. BMC Res Notes. 2012;5(1):396. https://doi.org/10.1186/1756-0500-5-396.

36. Fasola FA, Adekanmi AJ. Haematological profile and blood transfusion pattern of patients with sickle cell anaemia vary with spleen size. Ann Ib Postgrad Med. 2019;17(1):30-8.

37. Carlson J, Nash GB, Gabutti V, al-Yaman F, Wahlgren M. Natural protection against severe plasmodium falciparum malaria due to impaired rosette formation. Blood. 1994;84(11):3909-14. https://doi.org/10.1182/blood. V84.11.3909.bloodjournal84113909.

38. Beet EA. The genetics of the sickle-cell trait in a bantu tribe. Ann Eugenics. 1949;14(4):279-84. https://doi.org/10.1111/j.1469-1809.1947.tb02402.x.

39. Weatherall DJ, Miller LH, Baruch DI, Marsh K, Doumbo OK, Casals-Pascual C, et al. Malaria and the red cell. Hematol Am Soc Hematol Educ Program. 2002;2002(1):35-57. https://doi.org/10.1182/asheducation-2002.1.35.

40. Otieno RO, Ouma C, Ong'echa JM, Keller CC, Were T, Waindi EN, et al. Increased severe anemia in HIV-1-exposed and HIV-1-positive infants and children during acute malaria. AIDS. 2006;20(2):275-80. https://doi.org/10.1 097/01.aids.0000200533.56490.b7

41. Stoute JA, Odindo AO, Owuor BO, Mibei EK, Opollo MO, Waitumbi JN. Loss of red blood cell-complement regulatory proteins and increased levels of circulating immune complexes are associated with severe malarial anemia. J Infect Dis. 2003;187(3):522-5. https://doi.org/10.1086/367712.

42. Waitumbi JN, Opollo MO, Muga RO, Misore AO, Stoute JA. Red cell surface changes and erythrophagocytosis in children with severe plasmodium falciparum anemia. Blood. 2000;95(4):1481-6. https://doi.org/10.1182/blood. V95.4.1481.004k15_1481_1486.

43. Eleonore NLE, Cumber SN, Charlotte EE, Lucas EE, Edgar MML, Nkfusai CN, et al. Malaria in patients with sickle cell anaemia: burden, risk factors and outcome at the Laquintinie hospital, Cameroon. BMC Infect Dis. 2020;20(1): 40. https://doi.org/10.1186/s12879-019-4757-x.

44. Ladhani S, Lowe B, Cole AO, Kowuondo K, Newton CR. Changes in white blood cells and platelets in children with falciparum malaria: relationship to disease outcome. Br J Haematol. 2002;119(3):839-47. https://doi.org/10.104 6/j.1365-2141.2002.03904.x

45. Antwi-Baffour S, Kyeremeh R, Buabeng D, Adjei JK, Aryeh C, Kpentey G, et al. Correlation of malaria parasitaemia with peripheral blood monocyte to lymphocyte ratio as indicator of susceptibility to severe malaria in Ghanaian children. Malar J. 2018;17(1):419. https://doi.org/10.1186/s12936-018-2569-x.

46. Belcher JD, Marker PH, Weber JP, Hebbel RP, Vercellotti GM. Activated monocytes in sickle cell disease: potential role in the activation of vascular endothelium and vaso-occlusion. Blood. 2000;96(7):2451-9. https://doi.org/1 0.1182/blood.V96.7.2451

47. Inwald DP, Kirkham FJ, Peters MJ, Lane R, Wade A, Evans JP, et al. Platelet and leucocyte activation in childhood sickle cell disease: association with nocturnal hypoxaemia. Br J Haematol. 2000;111(2):474-81. https://doi.org/1 0.1046/j.1365-2141.2000.02353.x.

48. Wun T, Cordoba M, Rangaswami A, Cheung AW, Paglieroni T. Activated monocytes and platelet-monocyte aggregates in patients with sickle cell disease. Clin Lab Haematol. 2002;24(2):81-8. https://doi.org/10.1046/j.13 65-2257.2002.t01-1-00433.x 
49. Guarda CC, Silveira-Mattos PSM, Yahouedehou S, Santiago RP, Aleluia MM, Figueiredo CVB, et al. Hydroxyurea alters circulating monocyte subsets and dampens its inflammatory potential in sickle cell anemia patients. Sci Rep. 2019:9(1):14829. https://doi.org/10.1038/s41598-019-51339-x.

50. Adedapo AD, Falade CO, Kotila RT, Ademowo GO. Age as a risk factor for thrombocytopenia and anaemia in children treated for acute uncomplicated falciparum malaria. J Vector Borne Dis. 2007;44(4):266-71.

51. Beale PJ, Cormack JD, Oldrey TB. Thrombocytopenia in malaria with immunoglobulin (IgM) changes. Br Med J. 1972;1(5796):345-9. https://doi. org/10.1136/bmj.1.5796.345.

52. Erhart LM, Yingyuen K, Chuanak N, Buathong N, Laoboonchai A, Miller RS, et al. Hematologic and clinical indices of malaria in a semi-immune population of western Thailand. Am J Trop Med Hyg. 2004;70(1):8-14. https://doi.org/10.4269/ajtmh.2004.70.8.

53. Lathia TB, Joshi R. Can hematological parameters discriminate malaria from nonmalarious acute febrile illness in the tropics? Indian J Med Sci. 2004; 58(6):239-44.

54. Bashawri LA, Mandil AA, Bahnassy AA, Ahmed MA. Malaria: hematological aspects. Ann Saudi Med. 2002;22(5-6):372-6. https://doi.org/10.5144/0256-4 947.2002.372.

55. Chiwakata CB, Hemmer CJ, Dietrich M. High levels of inducible nitric oxide synthase mRNA are associated with increased monocyte counts in blood and have a beneficial role in plasmodium falciparum malaria. Infect Immun. 2000;68(1):394-9. https://doi.org/10.1128//Al.68.1.394-399.2000.

56. Modiano D, Sirima BS, Konaté A, Sanou I, Sawadogo A. Leukocytosis in severe malaria. Trans Royal Soc oTrop Med Hyg. 2001;95(2):175-6. https:// doi.org/10.1016/S0035-9203(01)90152-X.

57. Chiang EY, Frenette PS. Sickle cell vaso-occlusion. Hematol Oncol Clin North Am. 2005;19(5):771-84, v. https://doi.org/10.1016/j.hoc.2005.08.002.

58. Hoffbrand AV, Catovsky D, Edward GD, Anthony RG. Postgraduate hematology. 6th ed. Birmingham: Wiley-Blackwell; 2010.

59. Kotepui M, Phunphuech B, Phiwklam N, Chupeerach C, Duangmano S Effect of malarial infection on haematological parameters in population near Thailand-Myanmar border. Malar J. 2014;13(1):218. https://doi.org/10.11 86/1475-2875-13-218.

60. Wei KY, Yan Q, Tang B, Yang SM, Zhang PB, Deng MM, et al. Hookworm infection: a neglected cause of overt obscure gastrointestinal bleeding. Korean J Parasitol. 2017;55(4):391-8. https://doi.org/10.3347/kjp.2017.55.4.3 91.

61. Were T, Davenport GC, Hittner JB, Ouma C, Vulule JM, Ong'echa JM, et al. Bacteremia in Kenyan children presenting with malaria. J Clin Microbiol. 2011;49(2):671-6. https://doi.org/10.1128/JCM.01864-10.

\section{Publisher's Note}

Springer Nature remains neutral with regard to jurisdictional claims in published maps and institutional affiliations.

Ready to submit your research? Choose BMC and benefit from:

- fast, convenient online submission

- thorough peer review by experienced researchers in your field

- rapid publication on acceptance

- support for research data, including large and complex data types

- gold Open Access which fosters wider collaboration and increased citations

- maximum visibility for your research: over $100 \mathrm{M}$ website views per year

At $\mathrm{BMC}$, research is always in progress.

Learn more biomedcentral.com/submissions 